\title{
Iliac Lymph Sac
}

National Cancer Institute

\section{Source}

National Cancer Institute. Iliac Lymph Sac. NCI Thesaurus. Code C34191.

Two of six primary lymph sacs found during the embryonic period that are the first

precursors to lymph node development, and which are located at the junction of the iliac and postcardinal veins and drain lymph from the legs. 